\title{
CRIANÇAS COM TRANSTORNO DE DÉFICIT DE ATENÇÃO/HIPERATIVIDADE: DIFICULDADES DE APRENDIZAGEM NO ÂMBITO ESCOLAR ${ }^{1}$
}

\author{
Ana Beatriz Batista Sousa-UNIFSA ${ }^{2}$ \\ Ana Luiza Moura Oliveira-UNIFSA ${ }^{3}$ \\ Janaine Borges Lustosa-UNIFSA ${ }^{4}$ \\ Mariana Aurora Pereira de Azevedo-UNIFSA ${ }^{5}$ \\ Milena Luana Rodrigues Gomes-UNIFSA ${ }^{6}$ \\ Rita de Cássia Araújo de Sousa-UNIFSA ${ }^{7}$ \\ Milena Moura Fé Araújo Portela-UNIFSA ${ }^{8}$
}

\begin{abstract}
RESUMO
O Transtorno de Déficit de Atenção/Hiperatividade (TDAH) é caracterizado por um padrão de persistência de desatenção e/ou hiperatividade-impulsividade, que interfere no funcionamento e no desenvolvimento do indivíduo, de acordo com o DSM-V (APA, 2014). O objetivo do artigo em questão foi identificar as dificuldades enfrentadas pelos professores em sala de aula e as estratégias utilizadas para facilitar a inclusão e a aprendizagem dos alunos diagnosticados com TDAH. Para o desenvolvimento do estudo foi realizada uma revisão de literatura com pesquisa de abordagem qualitativa, no período de março a maio de 2019, por meio das bases de dados pela plataforma Scielo, Lilacs, EBSCOhost. Foram encontrados oito artigos a partir dos descritores buscados na área da psicologia, alinhados com os critérios de inclusão. Foram excluídos os artigos que não correspondiam ao objeto de estudo. Sobre os resultados encontrados, identificou-se a necessidade de um maior preparo dos profissionais da área da educação, bem como um número maior de projetos educacionais para o atendimento do público em questão. O estudo evidenciou a importância de um olhar especial do professor ao aluno, de modo a utilizar estratégias que possibilitem o desenvolvimento pedagógico do aluno. Foi analisado que os educadores não possuem estratégias específicas para lidar com crianças com TDAH, tanto pela falta de preparo, quanto pela "invisibilidade" do diagnóstico.
\end{abstract}

Palavras-Chave: Criança. TDAH. Dificuldades de aprendizagem.

\section{INTRODUÇÃO}

Caracterizado como um padrão de persistência de desatenção e/ou hiperatividadeimpulsividade, a criança com TDAH (Transtorno de Déficit de Atenção/Hiperatividade) tem uma alteração na atenção, dificuldade de manter o foco e a organização. $O$ indivíduo com TDAH pode ou não apresentar hiperatividade física, mas sempre existirá uma dispersão na realização de atividades, de acordo com o DSM-V (APA, 2014). Existe uma questão em torno do TDAH, que se

\footnotetext{
${ }^{1}$ Trabalho apresentado no Congresso Brasileiro Ciência e Sociedade (CBCS 2019), promovido pelo Centro Universitário Santo Agostinho, de 03 a 05 de outubro de 2019, Teresina-PI.

${ }^{2}$ Graduanda em Psicologia pelo Centro Universitário Santo Agostinho (UNIFSA). E-mail: bia-ana-10@hotmail.com

${ }^{3}$ Graduanda em Psicologia pelo Centro Universitário Santo Agostinho (UNIFSA). E-mail:analuiza_mo19@hotmail.com

${ }^{4}$ Graduanda em Psicologia pelo Centro Universitário Santo Agostinho (UNIFSA). E-mail:janainelustosa@hotmail.com

${ }^{5}$ Graduanda em Psicologia pelo Centro Universitário Santo Agostinho (UNIFSA). E-mail:mary.pazevedo@hotmail.com

${ }^{6}$ Graduanda em Psicologia pelo Centro Universitário Santo Agostinho (UNIFSA). E-mail:milena1luana@outlook.com

${ }^{7}$ Graduanda em Psicologia pelo Centro Universitário Santo Agostinho (UNIFSA). E-mail:ritaaraujobraz@gmail.com

${ }^{8}$ Mestre em Psicologia Experimental: Análise do Comportamento- PUC-SP. Centro Universitário Santo Agostinho (UNIFSA).E-mail:milenamourafe@hotmail.com
} 
baseia num fato próprio: não apresentam uma incapacidade, embora obtenham resultados inconsistentes e variáveis que dependem muito do grau e do tipo de motivação presente no seu contexto. Com isso, nem todas as crianças que apresentam níveis inadequados de atividade, impulsividade ou que não mantém uma atenção de forma consistente, devem ser vistas com TDAH. De acordo com SILVA (2014), um dos principais obstáculos encontrados por parte dos professores é a dificuldade no diagnóstico, que devido sua "invisibilidade", muitas vezes os comportamentos desses alunos, é interpretado como indisciplinado, "mal-educado", preguiçoso e inquieto. Para isso, o presente artigo buscou, por meio de um estudo bibliográfico, analisar as dificuldades enfrentadas pelos professores em sala de aula e quais estratégias utilizadas para facilitar a inclusão e a aprendizagem dos alunos diagnosticados com Transtorno de Déficit de Atenção/Hiperatividade.

\section{MATERIAL E MÉTODOS}

Utilizou-se o método de revisão da literatura com pesquisa de abordagem qualitativa e levantamento bibliográfico realizado no período de março a maio de 2019 , através da plataforma da BVS por meio de consultas feitas pela internet nas bases de dados Scielo, Lilacs, EBSCOhost.

Foram selecionados oito artigos, os descritores contidos como critérios de inclusão foram os trabalhos relacionados a crianças com TDAH, dificuldades de aprendizagem e ambiente escolar. Foram inclusos apenas artigos em português que abordassem a temática em estudo, independentemente do método de pesquisa, publicados nos últimos dez anos.

Sobre os critérios de exclusão, não foram utilizados artigos não relacionados ao objeto de estudo, artigos incompletos, pesquisas sem embasamentos, trabalhos que não tiveram metodologia clara e aqueles que não possuíam os descritores determinados pelos pesquisadores.

\section{RESULTADOS E DISCUSSÃO}

Constitui um verdadeiro desafio analisar as dificuldades enfrentadas por professores no âmbito escolar, isto porque não há, muitas vezes, o reconhecimento do TDAH em sala de aula.

No estudo de Coutinho et. al (2009) é analisada a concordância entre relato de pais e professores acerca dos sintomas do TDAH. Foi percebida na pesquisa realizada, a dificuldade do educador em identificar os sintomas de TDAH no âmbito escolar. Assim, vale ressaltar å imp: 978-65ância 
de possíveis palestras diante do assunto para os profissionais, e desenvolvimento de possibilidades para aprimoramento de estratégias pedagógicas. De forma complementar, outros dois artigos apresentaram informações semelhantes que vêm ratificar a dificuldade do professor em ajudar aluno com TDAH. No artigo: Transtorno de déficit de atenção com hiperatividade: classificação e classificados (BRZOZOWSKI; CAPONI, 2009) e no artigo: TDAH em alunos do ensino fundamental I (SOARES; MATOS, 2017), é apontada a dificuldade do docente de identificar o TDAH em sala de aula e como lidar de forma correta com os alunos com TDAH. A maioria dos artigos analisados retrata que os professores não possuem manejo adequado para lidar com esses alunos. Como conseguir ter um olhar cuidadoso e tão individualizados para uma grande quantidade de alunos e com turmas tão heterogêneas? Eis o grande desafio diário do professor. Como estratégia para a melhoria, é ressaltada a importância do desenvolvimento de oficinas que podem fortalecer a aprendizagem dos educadores para instrumentalizá-los para uma condução adequada para com esse aluno.

Couto, Gomes e Júnior Melo (2010) relatam em seu artigo sobre a desatenção que o aluno tem em decorrência do TDAH, uma alta frequência de desatenção que o aluno apresenta ao professor quando lhe é dirigida a palavra. Aponta também sobre a dificuldade para manter a atenção em tarefas ou atividades lúdicas. Isto porque, o professor não utiliza de estratégias interventivas para manejar casos dessa natureza. Há a dificuldade de manejo entre o professor e o aluno, já que o professor não possui recursos específicos para lidar com essa demanda, nem uma equipe multidisciplinar para o suporte pedagógico.

Outro estudo analisado foi o de Carmo, Rodrigues e Sousa (2010), que aborda possíveis relações entre TDAH e aprendizagem da Matemática. Foi descrito nesse artigo, um estudo de caso no qual eram avaliados aspectos relevantes da vida de um aluno no âmbito escolar, e foram percebidos reflexos das suas relações familiares em seu desempenho escolar. Ressaltou-se a importância de que o aluno se sinta em um ambiente acolhedor e saiba buscar sua identidade no contexto escolar. O artigo trouxe uma reflexão sobre as metodologias utilizadas pelos educadores no âmbito escolar e a importância de um professor com uma postura acolhedora em sala de aula. As metodologias relatadas na pesquisa foram: utilizar um tom adequado para falar com o aluno, ensinar regras, dar oportunidade aos alunos praticarem o que desejarem, apresentando a eles uma opinião sobre os combinados, sempre elogiar quando conseguir atingir as metas estabelecidas, oferecer atividades que possibilitem a locomoção em classe e em outros ambientes da escola, etc.

Na mesma direção do estudo supracitado, é destacado o estudo de Silva e Dias (2014) que trata sobre as estratégias de metodologia para o professor trabalhar em sala de aula. Para as autoras, o educador deve estabelecer empatia, responsabilidade e cuidado para esse aluno, isso vai 
possibilitar um maior rendimento diante da sua aprendizagem. Almeida (2004) complementa, mencionando que o ensino deve atentar para as necessidades dos alunos no que tange seu desenvolvimento afetivo-cognitivo.

Sobre métodos incentivadores, ressalta-se o estudo de Dartora et. Al (2012) intitulado: alunos com TDAH: aprendendo através de tecnologias. O estudo, descreve a realidade de uma escola privada que faz uso de aparelhos de computação para alunos com TDAH. Tal recurso é reconhecido no estudo, como uma forma de estímulo importante para o aluno, pois possibilita um melhor desempenho do alunado acerca dos conteúdos apresentados, mas para isso deve haver todo um planejamento das aulas. Os professores do estudo, salientam a importância da inclusão, a partir de um olhar mais vasto para essas crianças. A maioria dos educadores relata que sabe distinguir uma criança com TDAH e chama a atenção para a necessidade do conhecimento do professor sobre essas especificidades.

Por fim, os autores Cunha e Santos (2017) destacam que o professor é visto como um provedor de saúde, já que a maior parte do tempo dessas crianças está no ambiente escolar. O artigo traz vários tipos de estratégias. São elas: estratégias iniciais: não criticar e não apontar desacertos, fazer o uso da metodologia conhecida como "aprendizagem ativa", que usa tarefas em duplas, trabalhos e respostas orais, etc.; estratégias comportamentais: aplicar algum tipo de restrição com consistência e bom senso, combinar sinais discretos para chamar atenção ou lembrar acordos (IMAGUTI, 2011); parceria com a família: Goldstein e Goldstein (2002) propõe que os pais determinem horários e local específico para o estudo das crianças.; ludicidade e arte: recomendase uso de sucatas, atividade corporais cenestésica e jogos com regras, etc.) que podem ser interventivas no processo de ensino-aprendizagem desse aluno. Enfim, o profissional deve direcionar através de um manejo adequado, estímulos que reforcem o aprendizado da criança, levando sua singularidade.

A literatura aponta também a importância do apoio familiar a essas crianças. O papel dos pais é essencial no desenvolvimento da criança com TDAH. Em casa ela deve seguir uma rotina bem organizada e receber estimulação adequada. Devem ter um ambiente tranquilo e calmo para fazer as tarefas, possibilitando melhor concentração. O professor estando preparado e em sintonia com os pais poderá orientá-los sobre como lidar com seus filhos.

As intervenções psicológicas e psicopedagógicas são também fundamentais no desenvolvimento de estratégias que possam facilitar o processo de ensino-aprendizagem. Além disso, podem propiciar uma relevante fonte de apoio à família nesse manejo, uma vez que, tal trabalho deve ser contínuo e não restrito à escola (PEIFFNER, 2002). Há necessidade de apoio de 
uma equipe multidisciplinar (COUTO; GOMES; JÚNIOR; MELO, 2010). Buscar estratégias corretas e fundamentadas, irá beneficiar muito a criança com TDAH a ter uma vida mais equilibrada e uma melhor convivência nos mais diversos ambientes onde esteja inserida.

\section{CONCLUSÕES}

Tendo em vista os aspectos observados, é possível reconhecer a importância do conhecimento mais aprofundado sobre as estratégias que podem ser utilizadas pelos professores no direcionamento das suas aulas com alunos com TDAH. Embora não seja possível generalizar os resultados encontrados no presente estudo, os mesmos sugerem a existência de pouco conhecimento dos docentes acerca do TDAH e de como lidar com essa realidade em sala de aula.

Há a necessidade de uma postura diferenciada do docente com o aluno com TDAH. De acordo Fazenda (2010, p.111) "para o professor conseguir desenvolver sua prática pedagógica com sucesso, ele precisa de três atributos: preparo, espera e coragem, pois todo fazer pedagógico deve ser baseado no acolhimento, na continuidade, na persistência, coerência e consistência", mas para isso ser possível, é necessário maior investimento na formação de profissionais da área da educação e um maior número de projetos educacionais, aumentando a probabilidade do alcance de uma educação de qualidade para todos.

A dificuldade de encontrar na literatura científica, estratégias específicas para o manejo com alunos com TDAH, apenas reitera a necessidade gritante de mais estudos e mecanismos práticos para o fazer docente mais especializado.

\section{REFERÊNCIAS}

ALMEIDA, Ana Rita Silva. A emoção em sala de aula. 4.ed. Campinas: Papirus, 2004.

AMERICAN PSYCHIATRY ASSOCIATION (APA). Manual diagnóstico e estatístico de transtornos mentais - DSM-V. Porto Alegre: Artmed, 2014.

BRZOZOWSKI, Fabíola Stolf; CAPONI, Sandra. Transtorno de Déficit de Atenção com Hiperatividade: classificação e classificados. Revista de Saúde Coletiva, Rio de Janeiro, 2009.

CARMO, João dos Santos; RODRIGUES, Carolina Innocente; SOUSA, Maria do Carmo. Transtorno de conduta/TDAH e aprendizagem da Matemática: um estudo de caso. Revista Semestral da Associação Brasileira de Psicologia Escolar e Educacional. São Paulo, julho/dezembro de 2010. 
COUTINHO, Gabriel et al. Concordância entre relato de pais e professores para sintomas de TDAH: resultados de uma amostra clínica brasileira. Revista de Psiquiatria Clínica., São Paulo, v.36, n.3, 2009.

COUTO, Taciana de Souza; GOMES, Cláudia Roberta de Araújo; JÚNIOR MELO, Mario Ribeiro de. Aspectos neurobiológicos do transtorno do déficit de atenção e hiperatividade (TDAH): uma revisão. Ciências \& Cognição, Recife, 2010.

CUNHA, Alex Garcia; SANTOS, Halley. A criança com Transtorno do Déficit de Atenção e Hiperatividade: estratégias e ações para educadores. Revista Pedagógica, Chapecó-SC, jan./abr.2017.

DARTORA, Luiza Pereira et al. Alunos com TDAH: aprendendo através das tecnologias. Caxias do Sul, 2012.

FAZENDA, Ivani. Metodologia da Pesquisa educacional. São Paulo: Cortez, 2010.

GOLDSTEIN, San; GOLDSTEIN, Michel. Hiperatividade: Como desenvolver a capacidade de atenção da criança. 8. Ed. Campinas, SP: Papirus editora, 2002.

IAMAGUTI, Simone Silveira Peruzzi. TDAH: Integrando à Educação e à Saúde uma Visão Psicoeducativa. Revista Brasileira de Educação e Cultura, São Gotardo, v.1, n.4, p.64-88, jul./dez. 2011.

SILVA, Soeli Batista da; DIAS, Maria Angélica Dornelles. TDAH na escola estratégias de metodologia para o professor trabalhar em sala de aula. Revista Eventos Pedagógicos, nov./dez.2014.

SILVA, Ana Beatriz Barbosa. Mentes inquietas: TDAH- Desatenção, Hiperatividade e Impulsividade. 4. ed. São Paulo: Globo, 2014.

SOARES, Aline Raquel de Lima; MATOS, Ana Carolina Nunes de Matos. O TDAH em alunos do Ensino Fundamental I. Olinda: Psicologia. PT. O Portal dos Psicólogos,2017. 